\title{
TWO NEW SPECIES OF THE GENUS OTIOTHOPS (ARANEAE, PALPIMANIDAE) FROM THE VIRGIN ISLANDS*
}

\section{By Arthur M. Chickering}

\section{Museum of Comparative Zoology}

Otiothops walckenaeri MacLeay, I839, was established on the basis of a female from Cuba. Miss Bryant recognized the male and very briefly described it in 1940. O. oblongus Simon, I891 was described from a female taken on St. Vincent, B. W. I. The male remains unknown. I failed to collect any members of this family during my visit to this island in October 1966. O. lutzi Petrunkevitch, 1929, was also described from a female taken on Puerto Rico. The male has never been reported. I was again disappointed in not finding any members of this family during my period of collecting in Puerto Rico in January and February 1964. While collecting in Trinidad, W. I. in $1964 \mathrm{I}$ found both sexes of a new species described as $O$. carpenteri Chickering, 1966. While collecting in the American and British Virgin Islands in July and August, I966, I found specimens which seem to represent two additional species belonging to this very interesting genus. These are described in the following pages of this brief paper. As the matter now stands, six species of the genus Otiothops are now known from the West Indies. Two of these are known from both sexes, three are known only from females and the remaining species is known only from males. I think it safe to predict, however, that diligent searching in this region will yield several additional species.

Grant No. GB-5013 from the National Science Foundation made it possible for me to spend nearly four months collecting on nine West Indian islands in 1966 and is now helping me to continue my studies in the Museum of Comparative Zoology.

Types and all other specimens relating to the species described in this paper will be deposited in the Museum of Comparative Zoology, Harvard University.

\section{Otiothops casobus sp. nov.}

\section{Figures I-4}

The name of the species is an arbitrary combination of letters.

Female holotype. Total length $6.08 \mathrm{~mm}$. Carapace $2.73 \mathrm{~mm}$

*Manuscript received by the editor March 17, 1967 


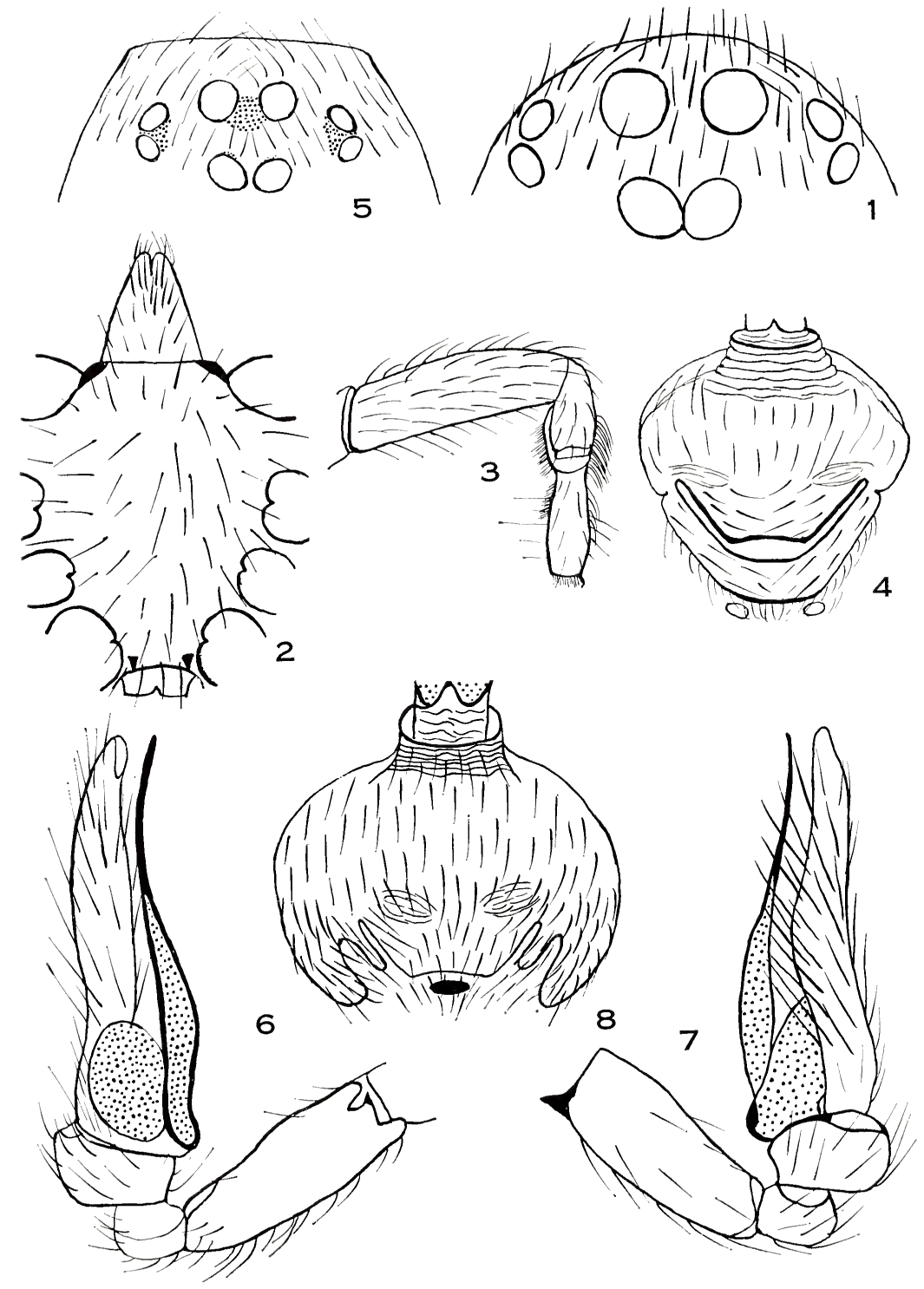

Chickering - Otiothops 
long; I.93 mm wide opposite interval between first and second coxae where it is widest; about I.I4 $\mathrm{mm}$ tall opposite interval between second and third coxae where it is tallest; height gradually increased from AME to beginning of posterior declivity the first half of which is very abrupt; thoracic fovea a fairly conspicuous pit near bottom of steep descent; surface finely granular and finely rugulose; anterior end bluntly rounded; posterior border squarely truncate. Eyes: eight in two rows; posterior row slightly longer than anterior row; viewed from above, anterior row gently recurved, posterior row strongly procurved thus bringing lateral eyes very close together (Fig. I). AME circular, all others oval with irregularities in outlines. Ratio of eyes AME : ALE : PME : PLE $={ }_{14}: \mathrm{I}_{3}$ : I 5 : I I (long axes used for measurements of oval eyes). AME dark; all others light with PME bright silvery. AME separated from one another by about $4 / 7$ of their diameter, from ALE by about $5 / 7$ of their diameter; PME in contact at posterior ends and obliquely placed; PME separated from PLE $7 / 5$ of their diameter. Lateral eyes separated by nearly one third of the long axis of PLE. Central ocular quadrangle wider in front than behind in ratio of about $7: 6$; longer than wide in front in ratio of about $8: 7$. Height of clypeus equal to nearly three times the diameter of AME; clypeus deeply grooved just above ventral margin. Chelicerae, maxillae and lip typical of females of the genus. Sternum: typical of the genus; extended between all coxae; most widely extended between first and second coxae; terminated opposite fourth coxae where there is a pair of short tubercles (Fig. 2) ; fourth coxae separated by about 6/5 of their width; surface coarsely granulate. Legs: 4123 in order of length; tibial index of first leg I6, of fourth leg II. First leg very robust with femur greatly elevated in proximal half; coxae I 423 in order of length and robustness; first metatarsus very short (Fig. 3); first tibiae, metatarsi and tarsi with iridescent ventroprolateral scopulae; all other metatarsi with distal, ventral scopulae; first patellae longest of the four; tarsal claws and claw tufts typical of the genus. Palp without a tarsal claw but with many tarsal bristles. Abdomen: typical of females of the genus; genital area

EXPLANATION OF PLATE 30

Figs. 1-4. Otiothops casobus sp. nov. Fig. 1, eyes of female holotype from above; fig. 2, sternum and lip; fig. 3, first tibia, metatarsus and tarsus, retrolateral view; fig. 4, genital area, ventral view.

Figs. 5-8. Otiothops pentucus sp. nov. Fig. 5, eyes of male holotype from above; figs. 6-7, left palp, prolateral and retrolateral views, respectively; fig. 8 , genital area, ventral view. 
obscurely distinctive (Fig. 4); scutum continued to region shortly above the pedicel; with two short spinnerets partly surrounded by a narrow, chitinized wall. Color in alcohol: carapace, sternum, chelicerae and lip all a rich, reddish brown; other mouth parts and legs considerably lighter with variations among them; first pair of legs and maxillae darkest; abdomen with dorsum almost black; venter nearly the same with faint lighter dots; genital region and scutum like sternum.

Type locality. The female holotype and a single immature individual were taken on Virgin Gorda, British Virgin Islands, August 2I, 1966.

\section{Otiothops pentucus sp. nov.}

Figures 5-8

The name of the species is an arbitrary combination of letters.

Male holotype. Total length $4.8 \mathrm{I} \mathrm{mm}$ (cephalothorax and abdomen considerably separated). Carapace $2.05 \mathrm{~mm}$ long; $1.56 \mathrm{~mm}$ wide opposite second coxae where it is widest; $.99 \mathrm{~mm}$ tall; nearly level along midline from PME to beginning of steep posterior declivity opposite second coxae; posterior declivity very steep through dorsal half and then more gradual to posterior border; with a conspicuous median pit at bottom of steepest part of declivity; surface finely granular; with a fairly well developed coat of procurved hair. Eyes: eight in two rows as usual; positions essentially as described for other species in this genus (194I, I966). AME circular; all others oval with minor irregularities (Fig. 5). Ratio of eyes AME : ALE : PME : PLE = I2 : Io : I I : 8 (long axes used when eyes are not circular). AME separated from one another by about their radius, from ALE by about 2/3 of their diameter. Laterals separated by slightly less than I/3 of the diameter of ALE. PME separated from one another by nearly $\mathrm{I} / 5$ of their diameter, from PLE by a little more than I.5 times their diameter. Central ocular quadrangle a little wider in front than behind and longer than wide in front in ratio of about $4: 3$. Height of clypeus equal to nearly three times the diameter of $\mathrm{AME}$; ventral border grooved and with a narrow membranous margin. Chelicerae: typical of the genus; teeth and spines along fang groove essentially as described for $O$. macleayi Banks (I94I). Maxillae typical of the genus. Lip: longer than wide in ratio of about 2I : I9; sternal suture line clear but, apparently, not permitting movement. Sternum: surface conspicuously granular but reduced along the central region; conspicuously 
extended between coxae in typical fashion; with the usual pair of small tubercles at posterior end. Legs: 1423 in order of length; tibial index of first leg 15 , of fourth leg I2; scopulae as usual on first tibiae, metatarsi and tarsi and with considerable iridescence; small scopulae also on metatarsi 2-4; two claws and claw tufts as usual; trichobothria appear to be numerous on several segments. Palp: apparently quite distinctive; essential features shown in Figures 6-7. Abdomen: ovoid; only slightly flattened dorsoventrally; epigenital area with a well marked scutum reaching dorsally to surround the base of the abdomen (Fig. 8); two spinnerets as usual, with a narrow chitinous wall nearly surrounding spinnerets and anal tubercle.

Type locality. Male holotype, one male paratype and an immature specimen were taken on St. John, U. S. Virgin Islands on July 22, 1966. Two immature specimens previously assigned to $O$. lutzi Petrunkevitch (Chickering, 1966) are now placed in this new species.

BANKS, NATHAN

\section{SELECTED BIBLIOGRAPHY}

1929. Spiders from Panama. Bull. Mus. Comp. Zool., 69: 53-96, 4 pls.

Bryant, Elizabeth B.

1940. Cuban Spiders in the Museum of Comparative Zoology. Bull. Mus. Comp. Zool., 86(7) : 249-532, 22 pls.

Chickering, A. M.

1941. The Palpimanidae of Panama. Papers of the Michigan Acad. of Science, Arts, and Letters, 27, 1941.

1966. New Species of Palpimanidae (Araneae) from the West Indies. Psyche, 73 (3) : 208-216.

Petrunkevitch, Alexander

1929. The Spiders of Porto Rico. Pt. 1, Trans. Connecticut Acad. Arts and Sci., 30:7-158, 150 figs.

Simon, EUgene

1891. On the spiders of the Island of St. Vincent. Pt. 1. Proc. Zool. Soc. of London, Nov. 17, 1891. 


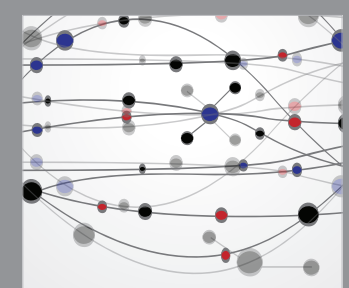

The Scientific World Journal
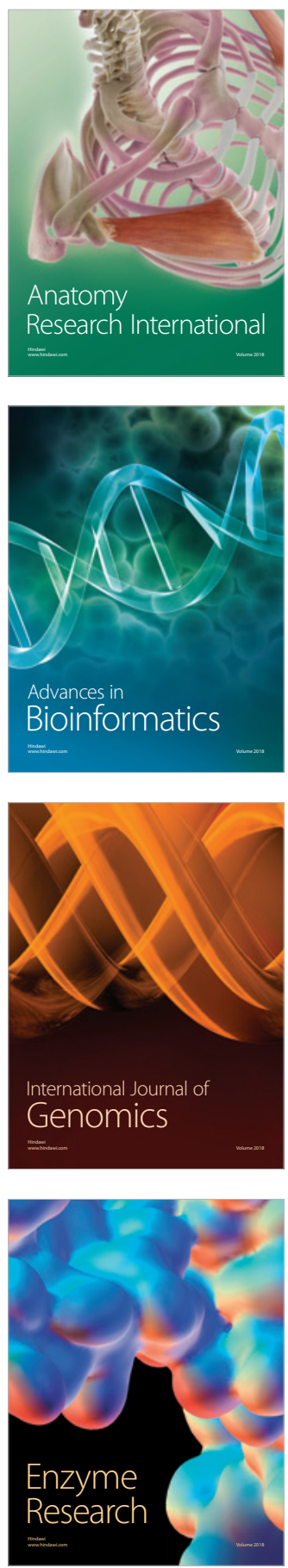
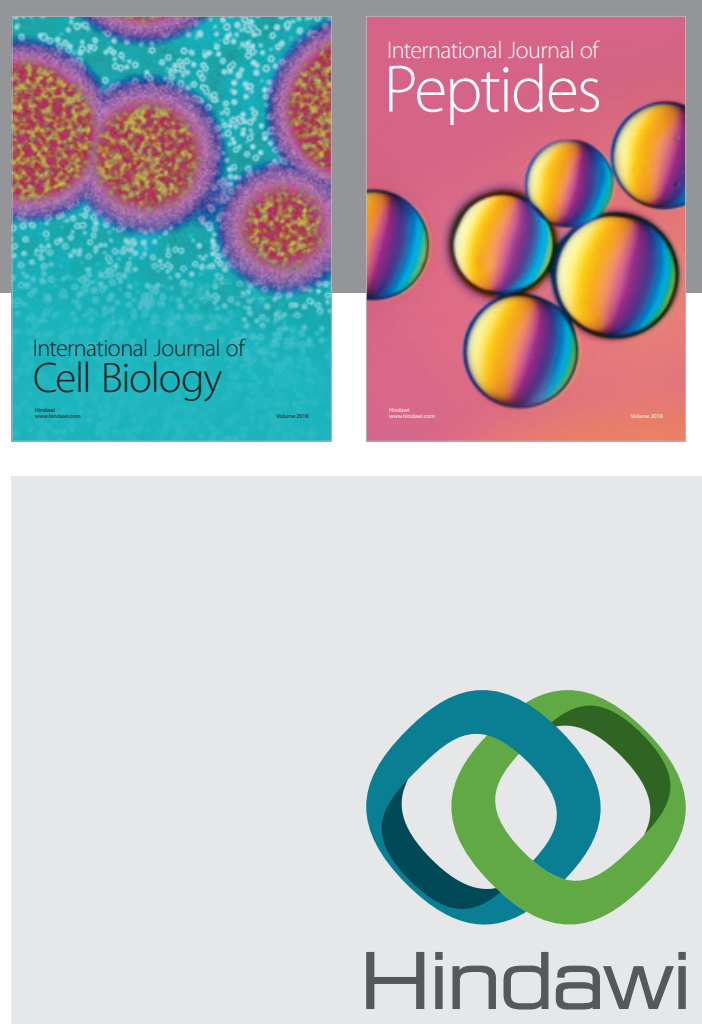

Submit your manuscripts at

www.hindawi.com
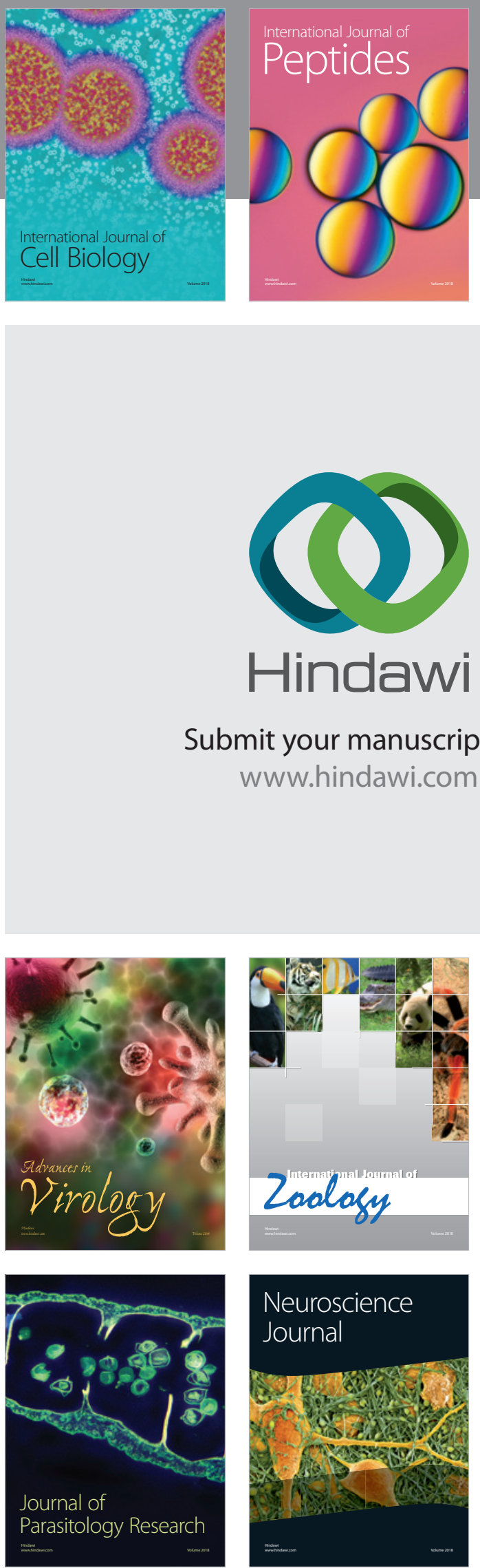
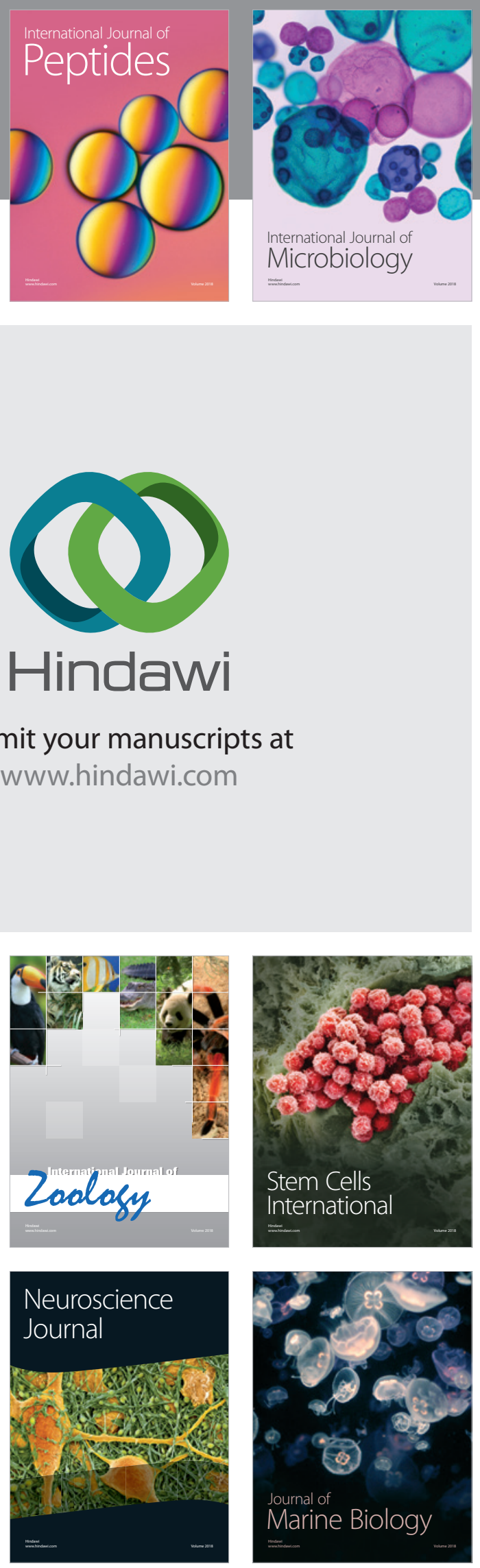
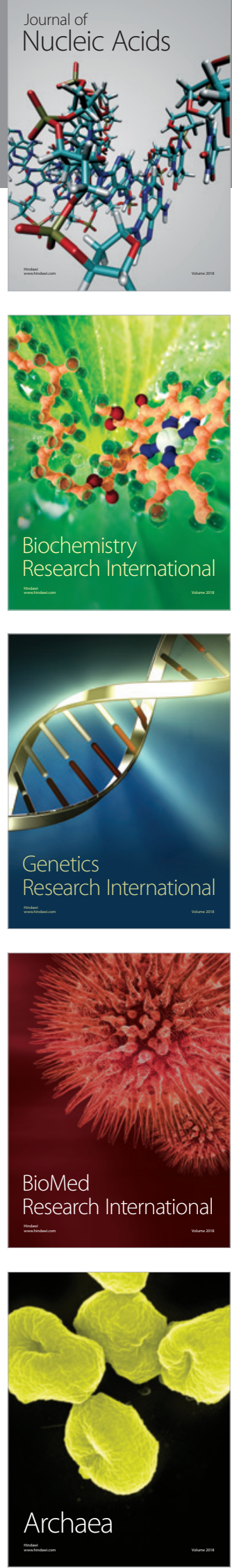